\title{
PENJARINGAN ATLET MELALUI KEJUARAAN BOLA VOLI TINGKAT PELAJAR DI KABUPATEN BENGKAYANG
}

\author{
Awang Roni Effendi ${ }^{1}$, Whalsen Duli Agus Lauh ${ }^{2}$,Iskandar ${ }^{3}$, Heri Rustanto ${ }^{4}$, \\ Anang Qosim ${ }^{5}$, Henry Maksum ${ }^{6}$, Rajidin ${ }^{7}$, Mohammad Sabransyah ${ }^{8}$ \\ 1,2,3,4,5,6,7,8 Program Studi Pendidikan Jasmani Kesehatan dan Rekreasi \\ Fakultas Pendidikan Olahraga dan Kesehatan \\ IKIP-PGRI Pontianak, Jalan Ampera No. 88 \\ 1e_mail: whalsenduli@gmail.com
}

\begin{abstract}
Abstrak
Tujuan dari pengabdian ini yaitu:1) Memberikan suatu kegiatan positif yaitu kegiatan olahraga sehingga dapat meningkatkan kesegaran jasmani serta menanamkan jiwa sportifitas bagi siswa, 2) Menumbuh kembangkan kegemaran siswa terhadap cabang olahraga bola voli, 3) Memfasilitasi minat dan bakat siswa pada cabang olahraga bola voli, 4) memotivasi siswa untuk memperoleh prestasi dalam olahraga khususnya cabang olahraga bola voli, 5) Sebagai ajang pemanduan bakat melalui pemantauan bibit-bibit atlet cabang olahraga bola voli. Metode yang digunakanya itu pemantauan terhadap siswa melalui penyelenggaraan tunamen bola voli. Hasil kegiatan adalah: 1) terdapat 12 orang pelajar putra dan 12 orang pelajar putri yang dinilai memiliki potensi untuk dikembangkan menjadi atlet bola voli tingkat pelajar, 2) kegiatan ini terlaksana dengan baik dan lancer serta para siswa sangat antusias untuk mengikuti turnamen ini, terbukti ada 24 tim putra dan 8 tim putri yang ikut bertanding.
\end{abstract}

Kata Kunci: Penjaringan atlet, turnamen bola voli tingkat pelajar

Abstract

The aims of this dedication are: 1) Providing a positive activity that is sports activities so as to increase physical fitness and instill a spirit of sportsmanship for students, 2) Develop students 'enjoyment of volleyball, 3) Facilitating students' interests and talents in volleyball, 4) motivating students to gain achievements in sports, especially volleyball,5) As a talent scouting event through monitoring the seeds of volleyball athletes. The method used is monitoring students through organizing volleyball tournaments. The results of the activities are: 1) there are 12 male students and 12 female students who are considered to have the potential to be developed into student-level volleyball athletes, 2) these activities are carried out well and smoothly and students are very enthusiastic to participate in this tournament, it was proven that there were 24 men's teams and 8 women's teams that competed.

Keyword: Athlete selection, volleyball tournament for students

\section{PENDAHULUAN}

Permainan bola voli memberikan kesempatan kepada pelajar untuk dapat mengembangkan berbagai kemampuan dalam aspek fisik, mental dan sosial sebagai dasar dalam pengembangan prestasi bola voli sebenanrnya. Hal ini selaras 
pula dengan teori kepelatihan bahwa permainan bola voli dimulai pada usia 11-12 tahun dan diharapkan mencapai puncaknya pada usia 20-25 tahun. Terkait dengan itu, analisis berikut ini menggambarkan nilai-nilai pendidikan yang terkandung dalam permainan bola voli yaitu: (1) nilai-nilai sosial seperti kerjasama dan toleransi; (2) nilai-nilai kompetitif seperti sikap pantang menyerah, berusaha merebut peluang; (3) nilai-nilai sportivitas seperti mau mengakui keunggulan lawan dan mengakui keterbatasan diri; (4) keterampilan berpikir dan kreativitas seperti penerapan taktik dalam situasi permainan yang komplek untuk memenangkan suatu permainan; (5) taat pada aturan karena dalam permainan dibatasi oleh aturan-aturan yang disepakati. Menurut PBVSI, (2005:17) bolavoli adalah olahraga yang dimainkan oleh dua tim dalam satu lapangan yang dipisahkan oleh sebuah net. Terdapat versi yang berbeda tentang jumlah pemain, jenis atau ukuran lapangan, angka kemenangan yang digunakan, untuk keperluan tertentu, namun pada hakikatnya permainan bolavoli bermaksud menyebarluaskan kemahiran bermain serta manfaat kepada setiap orang yang meminatinya.

Pembinaanprestasi bolavoli pada usia dini sangat penting pada suatu cabang olahraga karena pada anak usia dini perkembangan gerak sangat pesat dalam mengembangkan keterampilan dan bakat yang dimilikinya. Mendapatkan bibitbibit atlet yang berbakat akan lebih mudah ditemukan di satuan pendidikan baik di tingkat SD hingga ke SMA. Oleh karena itu usaha pembinaan bakat pada cabang olahraga bolavoli sangat diperlukan. Disamping sebagai suatu wadah pengembangan kemampuan individu, melalui berbagai kegiatan pembelajaran dan ekstrakurikuler, kegiatan olahraga bolavoli juga dapat dilakukan diluar aktivitas pendidikan yang tentunya lebih banyak memberikan sumbangan secara proporsi maupun kemampuan.

Melakukan aktivitas olahraga serta mengembangkan bakat dalam olahraga dapat dilakukan dengan berbagai cara serta dibermacam-macam tempat. Salah satu contoh peningkatan kemampuan dalam olahraga bolavoli dapat dilakukan dengan mengikuti klubbolavoli yang ada, mulaipadatingkatan yang paling sederhanahinggamenujupadatingkatanprofesional. Klub bolavoli akan memberikan berbagai jenis latihan untuk penguasaan ketrampilan bermain 
bolavoli dengan program-program latihan yang sudah tersusun sehingga memungkinkan bagi seseorang menguasai ketrampilan bermain bolavoli dengan baik. Dalam latihan untuk pembinaan prestasi bolavoli perlu adanya penguasaan serta penerapan teknik-teknik dasar bolavoli yang baik.

Permainan bola voli merupakan suatu permainan bola besar yang di mainkan oleh duaregu, masing-masing regu terdiri atas enam orang pemain yang bertujuan untuk mendapatkanangka sampai batas angka yang di tentukan dalam peraturan. Permainan bola voli yang sesungguhnya menurut Roji (2007: 10) ialah permainan yang di lakukan oleh regu, yang masing-masing regu berjumlah enam orang. Lama pertandingan adalah tiga atau lima set, atau kemenanga bisa di tentukan dengan selisih dua set. Masing-masing set adalah 25 angka (poin) dengan menggunakan rally point, yakni setiap bola mati di hitung menjadi poin.

Tujuan permainan bola voli adalah memperagakan teknik dan taktikmemainkan bola di lapangan untuk meraih kemenangan dalam setiap pertandingan(Muhajir,2006:7). Agar dapat memainkan bola voli dengan baik harus bisa menguasaiteknik dasar bola voli. Teknik dalam permainan bola voli dapat diartikan sebagai caramemainkan bola dengan efisien dan efektif sesuai dengan peraturan-peraturan yangberlaku untuk mencapai hasil yang optimal. Adapun teknik dasar dalam permainan bola voli yaitu servis, passing, umpan (setup), smesh, dan block.

Perkembangan dan pergaulan siswa di tingkat SMA sederajat yang notabene sudah memasuki usia remaja perlu diarahkan pada hal-hal positif. Tidak jarang anak di usia ini cenderung melakukan perbuatan melenceng bahkan terjerumus pada pergaulan negatif dan melawan hukum. Oleh karena itu, perlu adanya kegiatan-kegiatan yang dapat menyalurkan minat dan bakat mereka sehingga tidak terjerumus pada hal-hal negatif dan salah satu kegiatan yang dapat dilaksanakan yaitu event olahraga. Melalui kegiatan-kegiatan bidang keolahragaan, diharapkan siswa mampu menyalurkan minat dan bakatnya sekaligus mencapai prestasi maksimal. Dalam hal ini, kegiatan bidang keolahragaan yaitu turnamen bola voli merupakan salah satu pilihan yang rasional mengingat olahraga ini sangat digemari oleh siswa khususnya di kabupaten bengkayang dan melalui kegiatan ini 
diharapkan dapat menjadi wadah bagi para siswa untuk berprestasi di cabang olahraga bola voli serta sebagai ajang untuk memunculkan bibit-bibit atlet berbakat di kabupaten bengkayang. Adapun sekolah mitra dalam kegiatan ini yaitu MAN Bengkayang selaku tuan rumah kejuaraan.

\section{METODE}

Metode yang digunakanyaitupenyelenggaraan turnamen bola voli tingkat pelajar di Kabupaten bengkayang. Kategori yang dipertandingkan yaitu putra dan putri. Turnamen bola voli ini menggunakan sistem gugur atau setengah kompetisi dengan sistem pertandingan yaitu tiga set kemenangan. Adapun tahap-tahap pelaksanaankegitanyaitu: 1) Tahapan persiapan dalam kegiatan ini yaitu pembentukan panitia kegiatan, penyusunan proposal serta menjalin kerjasama dengan beberapa pihak terkait diantaranya Pengurus Cabang PBVSI Kabupaten Bengkayang dan MAN 1 Kabupaten Bengkayang yang akan dijadikan tuan rumah pelaksanaan turnamen.Adapun Panitia kegiatan ini terdiri dari Dosen Penjaskesrek yang tergabung dalam kelompok PKM ini serta alumni IKIP PGRI Pontianak yang berada di Kabupaten Bengkayang,(2) pelaksanaankegiatan ini dibagi menjadi beberapa tahap yaitu pendaftaran peserta, Pelaksanaan Technical Meeting (TM) dan pelaksanaan pertandingan, (3)Tahap Akhir dan evaluasi dimana pemenanghasilturnamen ini (Juara 1-IV) akan diberikan hadiah berupa piala, uang pembinaan serta sertifikat juara. Selain itu, pada tahap akhir ini akan dilakukan evaluasi terkait penjaringan atlet pelajar.

Sasaranobjekkegiataniniadalahpelajarputra maupun putri tingkat SMA/MA/SMK baik negeri maupun swasta di KabupatenBengkayang yang mewakili masing-masing sekolah dalam turnamen ini.

Sistem penjaringan atlet dilakukan dengan cara pemantauan selama turnamen berlangsung terhadap para pemain dari setiap tim yang bertanding oleh tiga unsur yaitu pelatih, guru penjas serta didampingi oleh Dosen Penjaskesrek IKIP PGRI Pontianak. Indikator penilaian yang digunakan meliputi aspek fisik, teknik dan mental pemain. Selain itu, faktor usia dan tingkatan kelas juga diperhatikan dimana lebih diutamakan pelajar putra putri yang usianya masih 
muda serta berada pada kelas $\mathrm{X}$ dan XI (sepuluh dan sebelas) dengan pertimbangan agar pelajar tersebut dapat terus dikembangkan menjadi atlet bola voli bengkayang untuk dua tahun ke depan. Penentuan atlet dilakukan dengan cara mengevaluasi setiap atlet yang berpotensi oleh ketiga unsur penilai/pemantau diatas. Keputusan diambil melalui kesepakatan dan hasil evaluasi.

\section{HASIL DAN PEMBAHASAN}

Kegiatan penjaringan atlet melalui penyelenggaraan turnamen bola voli tingkat pelajar putra dan putri se-Kabupaten Bengkayang telah dilaksanakan dengan baik dan lancar. Dalam pelaksanaannya, tidak ada kendala yang berarti dan kegiatan tersebut dapat dilaksanakan sesuai dengan rencana yang telah ditetapkan.

Turnamen bola voli tingkat pelajar se Kabupaten Bengkayang ini berlangsung selama 4 hari dari tanggal 27 - 30 April 2019. Tempat pelaksanaan turnamen ini yaitu lapangan bola voli Sekolah MAN Bengkayang. Panitia Pelaksana kegiatan ini yaitu tim Dosen PKM yang berjumlah 8 orang, dibantu alumni IKIP PGRI Pontianak yang berjumlah 3 orang dan bekerjasama dengan pihak MAN Bengkayang selaku tuan rumah. Adapun hasil yang dicapai dari kegiatan tersebut yaitu: 1) Dengan mengikuti turnamen bola voli ini, secara tidak langsung dapat menanamkan nilai-nilai sportifitas baik didalam maupun diluar pertandingan serta dapat meningkatkan kesegaran jasmani, 2) Melalui turnamen bola voli ini maka semakin menambah kecintaan siswa terhadap olahraga bola voli, terbukti dari banyaknya permintaan dari siswa agar turnamen ini dapat dilaksanakan secara rutin setiap tahun, 3) Tersalurkannya minat dan bakat siswa dalam cabang olahraga bola voli, 4) motivasi siswa untuk mengikuti turnamen ini sangat tinggi terbukti dari banyaknya tim yang ikut ambil bagianyaitu 24 tim putra dan 8 tim putri yang ikut bertanding, bahkan beberapa sekolah dari luar Kabupaten Bengkayang juga mendaftar yaitu dari Singkawang dan Sambas, 5) melalui pemantauan dan penilaian dari pelatih, guru penjas dan Dosen maka terjaringlah 12 orang pelajar putra dan 12 orang pelajar putri yang dinilai memiliki potensi untuk dikembangkan menjadi atlet bola voli tingkat pelajar di 
Kabupaten Bengkayang. Adapun pemenang dan atlet yang terjaring dalam turnamen bola voli tingkat Pelajar putra dan putri se Kabupaten Bengkayang ini sebagai berikut:

Tabel 1. Juara Kategori Pelajar Putra

\begin{tabular}{cl}
\hline Juara & Tim / Nama Sekolah \\
\hline I (Satu) & SMA N 1 Sanggau Ledo \\
\hline II (Dua) & MAN Bengkayang \\
\hline III (Tiga) & MAN Kota Singkawang \\
\hline IV (Empat) & SMA N 2 Singkawang \\
\hline
\end{tabular}

Tabel 2. Juara Kategori Pelajar Putri

\begin{tabular}{cl}
\hline Juara & Tim / Nama Sekolah \\
\hline I (Satu) & MAN Bengkayang \\
\hline II (Dua) & SMA N 1 Sanggau Ledo \\
\hline III (Tiga) & SMA N 1 Jagoi Babang \\
\hline IV (Empat) & MAN Kota Singkawang \\
\hline
\end{tabular}

Berdasarkan hasil pemantauan yang telah dilakukan selama turnamen ini berlangsung maka pada tabel 3 dan 4 berikut ini, dipaparkan data dari pelajar putra dan putri yang telah terjaring sebagai atlet pelajar yang potensial untuk dapat dikembangkan menjadi atlet pelajar Kabupaten Bengkayang. Pelajar yang telah terjaring tersebut selanjutnya direkomendasikan kepada Pengcab PBVSI Kabupaten Bengkayang agar mendapatkan pembinaan lebih lanjut serta dikembangkan menjadi atlet profesional yang nantinya dapat mewakili Kabupaten Bengkayang pada event bola voli baik di lingkup Kalimantan Barat maupun Nasional. 
Tabel 3. Atlet Pelajar Putra

\begin{tabular}{cll}
\hline No. & \multicolumn{1}{c}{ Nama } & \multicolumn{1}{c}{ Asal Sekolah } \\
\hline 1. & Muhammad Fiki & MAN Bengkayang \\
\hline 2. & Gustriadi & MAN Bengkayang \\
\hline 3. & Ivan Kusuma Ari & MAN Bengkayang \\
\hline 4. & Hafis & MAN Bengkayang \\
\hline 5. & Anwar Galip & MAN Bengkayang \\
\hline 6. & Ridwan & MAN Bengkayang \\
\hline 7. & Yogi Bayu Prakoso & SMA N 1 Sanggau Ledo \\
\hline 8. & Nanda Pratama & SMA N 1 Sanggau Ledo \\
\hline 9. & Haikal & SMA N 1 Sanggau Ledo \\
\hline 10. & Wawi Ardiawan & SMA N 1 Sanggau Ledo \\
\hline 11. & Bagus Cahyono & SMA N 1 Jagoi Babang \\
\hline 12. & Didik Purwanto & SMA N 1 Jagoi Babang \\
\hline
\end{tabular}

Tabel 4. Atlet Pelajar Putri

\begin{tabular}{cll}
\hline No. & \multicolumn{1}{c}{ Nama } & \multicolumn{1}{c}{ Asal Sekolah } \\
\hline 1. & Reni Kusuma Dewi & SMA N 1 Sanggau Ledo \\
\hline 2. & Sebastiana Hana & SMA N 1 Sanggau Ledo \\
\hline 3. & Gilta Nur Purwaningsih & SMA N 2 Ledo \\
\hline 4. & Oktarina Fitri & SMA N 2 Ledo \\
\hline 5. & Hana Fitria & SMA N 3 Bengkayang \\
\hline 6. & Mona Riswani & SMA N 3 Bengkayang \\
\hline 7. & Endang & MAN Bengkayang \\
\hline 8. & Mamar Rissinin & MAN Bengkayang \\
\hline 9. & Nurma Mega & MAN Bengkayang \\
\hline 10. & Dita Ayu Purba Sari & MAN Bengkayang \\
\hline 11. & Iis Rismati & MAN Bengkayang \\
\hline 12. & Sundari & MAN Bengkayang \\
\hline
\end{tabular}


Keselarasan kehidupan jasmani dan rohani pada manusia dapat dicapai salah satunya dengan melakukan kegiatan olahraga. Menurut Sajoto (1995: 5) ada empat dasar yang menjadi tujuan manusia melakukan olahraga yaitu:

1. Olahraga rekreasi yang menekankan tercapainya kesehatan jasmani dan rohani,

2. Olahraga pendidikan yang menekankan pada aspek pendidikan,

3. Olahraga profesional menekankan tercapainya keuntungan material,

4. Olahraga kompetitif atau prestasi menekankan pada kegiatan perlombaan dan pencapaian prestasi.

Bola voli adalah olahraga yang dapat dimainkan oleh anak-anak, remaja hingga orang dewasa serta wanita maupun pria. Dengan berolahraga salah satunya bola voli maka akan berkembang secara baik unsur-unsur kemampuan fisik dan perkembangan mental, sosialdan kepribadian. Kontrol pribadi, disiplin, kerjasama rasa tanggung jawab hingga semangat sportifitas akan ikut berkembang dengan baik pula. Beberapa manfaat dari bermain bola voli diantaranya: 1) kerjasama 2) kecepatan bergerak, 3) lompatan yang tinggi dan4) kreatif (suharno 1985 : 21).

Ada banyak olahraga yang berkembang dan popoler dikalangan pelajar Kabupaten Bengkayang namun olahraga bola voli adalah salah satu olahraga yang paling populer jika dibandingkan dengan olahraga lain. Melihat kenyataan tersebut, maka untuk meningkatkan kualitas dan prestasi cabang olahraga bola voli di Bengkayang merupakan tanggung jawab semua unsur terkait. Untuk mewujudkan prestasiolahraga bola voli dibutuhkan kerja keras, berlatih secara sistematis serta pola pembinaan yang tepat. Pemilihan bibit atlet yang tepat, organisasi yang baik, dana yang memadai, prasarana dan sarana yang mendukung, pelatih yang berkualitas, riset dan teknologi yang baik merupakan komponenkomponen yang berpengaruh terhadap pencapaian prestasi tersebut, yang mana merupakan kesatuan yang saling berhubungan dan tidak dapat dipisahkan.

Unsur-unsur yang penting serta mendukung dalam upaya meningkatkan prestasi olahraga bola voli antara lain pembinaan teknik, pembinaan fisik, pembinaan taktik dan pembinaan kematangan juara. Disamping pembinaan tersebut diatas, sebagai upaya untuk meningkatkan prestasi olah raga maka perlu 
terus dilaksanakan pembinaan pada usia dini yaitu melalui penjaringan dan pemantauan bakat, pembibitan, pendidikan dan pelatihan olahraga prestasi yang didasarkan pada ilmu pengetahuan dan teknologi secara lebih efektif dan efisien.

Langkah penjaringan atlet saja tidak cukup. Perlu adanya suatu wadah pembibitan yang diarahkan dalam rangka memberikan kontribusi melalui suatu kegiatan yang terpusat, dan dikembangkan lebih lanjut ke Pusat Pendidikan dan Latihan Olahraga Pelajar. Atlet-atlet yang telah terjaring tersebut perlu dididik dan dilatih secara khusus untuk menghadapi even-even yang diselenggarakan daerah POPDA (Pekan Olahraga Pelajar Daerah) hingga ke POPNAS(Pekan Olahraga Pelajar Nasional). Melalui pembinaan yang berkelanjutan maka potensi untuk berprestasi akan semakin besar.

Prestasi maksimal merupakan tujuan dan obsesi dari setiap atlet yang menekuni suatu cabang olahraga. Keberhasilan dan prestasi atlet tidak lepas dari dukungan berbagai pihak, oleh sebab itu perlu adanya sinergi semua komponen terkait di Kabupaten bengkayang untuk mencapai tujuan tersebut. Salah satunya melalui pelaksanaan turnamen bola voli tingkat pelajar untuk merangsang dan memacu para siswa agar menggemari olahraga ini. Selain itu, melalui penyelenggaraan turnamen bola voli juga diharapkan munculnya bibit-bibit atlet berbakat khususnya tingkat pelajar.

\section{SIMPULAN}

Simpulandarikegiatan PPM ini adalahkegiatan penjaringan atlet melalui penyelenggaraan turnamen bola voli tingkat pelajar putra dan putri se-Kabupaten Bengkayang telah terlaksana dengan baik dan lancar. Dalam pelaksanaannya, tidak ada kendala yang berarti dan kegiatan tersebut dapat dilaksanakan sesuai rencana yang telah ditetapkan. Hasil yang diperoleh yaitu terjaringnya 12 orang $\begin{array}{llll}\text { pelajarputradan } & 12 & \text { orang } & \text { pelajarputri }\end{array}$ dinilaimemilikipotensiuntukdikembangkanmenjadiatlet bola volitingkatpelajar di KabupatenBengkayang serta parasiswasangatantusiasuntukmengikutiturnamenini, terbuktiada 24 timputradan 8 timputri yang ikutbertanding. 


\section{UCAPAN TERIMA KASIH}

Terima kasih diucapkan kepada IKIP-PGRI Pontianak yang telah mendanai Pengabdian Kepada Masyarakat tahun anggaran 2019, sehingga operasional kegiatan dapat teratasi. Selain itu juga, diucapkan terimakasih kepada MAN Bengkayang yang telahbersedia menjadi tuan rumah dan menyediakan fasilitas yang diperlukan selama turnamen berlangsung, sehingga kegiatan ini berjalan dengan sukses.

\section{DAFTAR PUSTAKA}

Muhajir, 2006. Pendidikan Jasmani Teori dan Praktik I. Jakarta : Erlangga.

PBVSI, 2005. Peraturan Permainan Bola Voli. Jakarta: PB.PBVSI.

Roji, 2007. Pendidikan Jasmani Olahraga dan Kesehatan untuk SMP Kelas VII. Jakarta: Erlangga.

Sajoto, 1995. Pengembangan dan Pembinaan Kekuatan Kondisi Fisik dalam Olahraga. Jakarta: Dahara Prize.

Suharno, 1985. Ilmu Kepelatihan Olahraga. Yogyakarta: FPOK IKIP Yogyakarta. 